1. Hwang T.S, Song J, Yoona $H$, et al (2005) "Morphometry of the nasal bones and piriform apertures in Koreans". Annals of Anatomy, 187, pp. 411-414.

2. Lee S.E., Yang T.Y, Han G.S, et al (2008) "Analysis of the nasal bone and nasal pyramid by three- dimensional computed tomography". Eur. Arch. Otorhinolaryngol, 265, pp. 421-424.

3. Williams B.A, Rogers T (2006) "Evaluating the accuracy and precision of cranial morphological traits for sex determination". J. Forensic Sci, 51, pp. 729-735.

4. Trân Thị Anh Tú (2003) Hình thái, cấu trúc tháp mũi người trưởng thành, Luận án tiến sỹ y học, Đai họ Y Dược TP Hồ Chí Minh, tr. 30-60.

5. Lazovic G.D, Daniel R.K, Janosevic L.B, et al (2015) "Rhinoplasty: The Nasal Bones - Anatomy and Analysis". Aesthetic Surgery Journal, 35 (3), pp. $255-263$

6. Hefner J.T, Linde K.C (2018) Atlas of Human Cranial Macromorphoscopic Traits, Elsevier Inc, pp. 155-171.

7. Prado F.B, Caldas R.A, Rossi A.C, et al (2011) "Piriform Aperture Morphometry and Nasal Bones Morphology in Brazilian Population by PosteroAnterior Caldwell Radiographys". Int. J. Morphol, 29 (2), pp. 393-398.

8. Tsai F.C, Liao C.K, et al (2010) "Analysis of Nasal Periosteum and Nasofrontal Suture with Clinical Implications for Dorsal Nasal Augmentation". Plastic And Reconstructive Surgery, 126 (3), pp. 1037-1047.

\title{
THỰC TRANG SÂU RĂNG CỦA MộT NHÓM NGƯờI KHIẾM THI TẠI MộT SỐ QUÂ̂N Ở HÀ NộI NĂM 2020 - 2021
}

\section{TÓM TẮT}

Mục tiêu: Nghiên cứu nhằm đánh giá thực trạng sâu rắng của người khiếm thị tai một số quẩn ở Hà Nội. Phương pháp nghiên cứu: Nghiên cứu mô tả cắt ngang. Kết quả: Trong tổng số 151 người khiếm thị (76 nam, 75 nữ) đến khám có 63 người bị sâu răng, tỷ lệ sâu răng là $41.7 \%$. Chỉ số sâu mất trám trung bình là 3.06. Số răng mất trung bình là 1.96. Số răng được trám trung bình là 0.22 . Kết luận: Cần có những biện pháp hố trơ giáo dục, can thiệp điều trị kịp thời, giúp cho người khiếm thị được quan tâm, chăm sóc tốt hơn.

Tư khóa: Người khiếm thị, sâu răng.

\section{SUMMARY}

PREVALENCE OF DENTAL CARIES OF

VISUALLY IMPAIRED INDIVIDUALS IN SOME DISTRICTS OF HA NOI

Objective: To assess the prevalence of dental caries in visually impaired individuals in some districts of $\mathrm{Ha}$ Noi. Subjects and methods: This crosssectional study was carried out on 151 visually impaired individuals in some district of $\mathrm{Ha}$ Noi. Results and conclusions: In the study, $41.7 \%$ of individuals had dental caries. The overall mean number of DMFT was 3.06; mean number of missing teeth was 1.96; and mean number of filled teeth was 0.22 . caries.

Keywords: Visually impaired individuals, dental

*Trường Đại học Y Hà Nội

Chiu trách nhiếm chính: Võ Trương Như Ngọc

Email: votruongnhungoc@gmail.com

Ngày nhận bài: 5/4/2021

Ngày phản biện khoa học: 6/5/2021

Ngày duyệt bài: 22/5/2021

\section{I. ĐẶT VẤN ĐỀ}

Trong nhóm bệnh răng miệng thì sâu răng là bệnh rất phổ biến, gặp ở tất cả các lứa tuổi, mọi quốc gia trên thế giới. Bệnh sâu răng nếu không được điêuu trị kịp thời sẽ dẫn đến những biến chứng nguy hiểm như viêm tủy răng, viêm quanh cuống, ảnh hưởng nặng nề tới sức nhai, phát âm, thẩm mỹ.

Người khiếm thị thường khó tiếp cận với các biện pháp thông tin giáo dục truyền thông cũng như gặp khó khăn trong việc chăm sóc răng miệng. Hơn nữa, bản thân người khiếm thị thường có cuộc sống, hoàn cảnh khó khăn. Chỉ khi có triệu chứng đau răng rôi mới có nhu câu điêu trị. Mặt khác ở nước ta hiện nay những điều tra về bệnh sâu răng trên người khiếm thị chưa có nhiêu. Vì vậy, chúng tôi tiến hành nghiên cứu này với mục tiêu nhận xét thực trạng sâu răng của người khiếm thị tại một số quận ở Hà Nội năm 2020 - 2021.

\section{II. ĐỐl TƯƠNG VÀ PHƯƠNG PHÁP NGHIÊN CỨU}

2.1. Thời gian và địa điểm nghiên cứu: Ngày 14 tháng 3 năm 2021 tại nhà A5 bệnh viện Đại học Y Hà Nội.

2.2. Đối tượng nghiên cứu, Là người khiếm thị từ hội người mù một số quận ở Hà Nội

Thiết kế nghiên cứu, cõ̃ mẫu, cách chọn mẫu

Thiết kế nghiên cứu: là nghiên cứu cắt ngang mô tả

Cỗ mẫu được tính theo công thức:

$n=\frac{Z^{2}(1-a / 2) p(1-p)}{d^{2}}$ 
Trong đó. $\mathrm{n}$ : cõ mẫu cần thiết; $\mathrm{p}: 0.72$ (tỷ lệ sâu răng trên nhóm học sinh khiếm thị từ 6 đến 19 tuổi năm 2014 trong nghiên cứu của tác giả Phạm Thị Diệp $)^{1}$; d: độ chính xác mong muốn, chọn d=0.07; Z(1-a/2): =1.96 với độ tin cậy 95\%.

Theo lý thuyết chúng tôi cần có cõ mẫu cho nghiên cứu là 158 . Tuy nhiên buổi khám bệnh chỉ có 151 hội viên đến khám nên chúng tôi tiến hành nghiên cứu với cỡ mẫu là 151.

2.3. Các biến số trong nghiên cứu. Các thông tin về tuổi, giới và các yếu tố liên quan khác được ghi nhận theo mẫu phiếu phỏng vấn.

\subsection{Kỹ thuật thu thập thông tin}

Tiêu chuẩn sử dụng trong đánh giá sâu răng:

Chúng tôi sử dụng tiêu chuẩn của hệ thống đánh giá sâu răng quốc tế ICDAS trên lâm sàng.

Nguyên tắc chung: dùng bông lau sạch răng, khám và ghi nhận tình trạng sâu, mất, trám răng.

Xử lý số liệu: Số liệu được làm sạch, nhập bằng phần mềm Epidata. Phẩn tích bằng phẩn mềm SPSS 16.

2.5. Hạn chế sai số trong nghiên cứu. Các bác sĩ được tập huấn và chuẩn hóa khám lâm sàng.

2.6. Đạo đức nghiên cứu: Người khiếm thị được giải thích về nghiên cứu và đồng ý tham gia nghiên cứu. Quy trình khám được đảm bảo để không gây ra bất kì ảnh hưởng xấu nào cho người khiếm thị. Mọi thông tin của đề tài chỉ phục vụ cho nghiên cứu.

\section{KẾT QUẢ NGHIÊN CỨU}

3.1. Đặc điểm chung của đối tượng nghiên cứu. Tổng số người khiếm thị tham gia nghiên cứu là 151 người, trong đó có 76 nam chiếm 50.33\%, 75 nữ chiếm 49.67\%. 151 người đến khám là người trưởng thành, nhóm tuổi từ 18 đến 39 chiếm $33.77 \%$, nhóm người từ 40 đến 59 chiếm 39.74\%, nhóm người trên 60 tuổi chiếm $26.49 \%$.

Trình độ học vấn: có 6 người không đi học chiếm 3.97\%, 64 người trình độ dưới trung học phổ thông chiếm 42.39\%; 44 người hoàn thành trung học phổ thông chiếm 29.14\%; có 34 người hoàn thành đại học, cao đẳng chiếm $22.52 \%$, số người học sau đại học chiếm tỷ lệ thấp với 1.99\%.

Người khiếm thị chủ yếu sống cùng gia đình; chiếm $93.38 \%$; có 10 người ở một mình chiếm $6.62 \%$.

3.2. Thực trạng bệnh sâu răng ở đối tượng nghiên cứu

Tỳ lệ sâu răng chung: có 63 người sâu răng, chiếm $41.7 \%$.

Bảng 1. Chi số DMFT theo giới

\begin{tabular}{|c|c|c|c|c|c|}
\hline \multirow{2}{*}{ Giới } & \multirow{2}{*}{$\begin{array}{c}\text { Số } \\
\text { Iượng }\end{array}$} & \multicolumn{4}{|c|}{ Chỉ số } \\
\cline { 3 - 6 } & DT & MT & FT & DMFT \\
\hline Nữ & 75 & 0.87 & 1.89 & 0.37 & 3.13 \\
\hline Nam & 76 & 0.89 & 2.02 & 0.07 & 2.98 \\
\hline Tống số & 151 & 0.88 & 1.96 & 0.22 & 3.06 \\
\hline
\end{tabular}

Nhận xét: Chỉ số DMFT của nam là 2.98 thấp hơn so với DMFT của nữ (3.13). Trung bình mỗi người khiếm thị có 0.88 răng sâu, chỉ có 0.22 các răng được trám.

\section{Bảng 2. Chi số DMFT theo nhóm tuôi}

\begin{tabular}{|c|c|c|c|c|c|}
\hline Nhóm & \multirow{2}{*}{$\begin{array}{c}\text { Số } \\
\text { tuối }\end{array}$} & lượng & \multicolumn{4}{|c|}{ Chí số } \\
\hline $\mathbf{1 8 - 3 9}$ & 51 & 0.84 & 0.75 & 0.18 & 1.76 \\
\hline $\mathbf{4 0 - 5 9}$ & 60 & 1.05 & 2.13 & 0.28 & 3.47 \\
\hline$\geq \mathbf{6 0}$ & 40 & 0.68 & 3.25 & 0.18 & 4.1 \\
\hline Tống số & 151 & 0.88 & 1.96 & 0.22 & 3.06 \\
\hline
\end{tabular}

Nhận xét: chỉ số DMFT của nhóm tuổi trên 60 là 4.1 lớn nhất, sau đó là DMFT của nhóm tuổi $40-59$ là 3.47, thấp nhất là DMFT của nhóm 18 - 39 tuổi với DMFT là 1.76.

\section{BÀN LUẬN}

Nghiên cứu được tiến hành trên 151 người khiếm thị, tỷ lệ nam chiếm $50.33 \%$, cao hơn không đáng kể so với nữ 49.67\%. Các đối tượng nghiên cứu nằm trong độ tuổi từ 18 đến trên 60 tuổi, đây là lứa tuổi bộ răng vĩnh viễn.

Qua thăm khám chúng tôi thu được kết quả 63 người bị sâu răng, chiếm $41.7 \%$, tỷ lệ sâu răng theo giới hầu như không có sự khác biệt. So sánh với tỷ lệ sâu răng trên học sinh khiếm thị lứa tuổi tữ 6 đến 19 tuổi trong nghiên cứu của tác giả Phạm Thị Diệp ${ }^{1}$ năm 2014 là $72 \%$ thì tỷ lệ này thấp hơn rất nhiều. Điều này có thể giải thích rằng đối tượng nghiên cứu của chúng tôi là người khiếm thị trưởng thành, thói quen và sở thích ăn đồ ngọt thường ít hơn các học sinh. Khi so sánh với tỷ lệ sâu răng trên người bình thường nhóm tuổi 18-34 của tác giả Trân Văn Trường ${ }^{2}$ và cộng sự năm 2001 trong báo cáo điêu tra sức khỏe răng miệng toàn quốc là $75.2 \%$ thì tỷ lệ của chúng tôi cũng thấp hơn. Trước khi thăm khám lâm sàng chúng tôi có hỏi về nghề nghiệp và điều kiện kinh tế nói chung, đa phần người khiếm thị có hoàn cảnh kinh tế khó khăn, hiếm khi sử dụng đồ ngọt giữa các bữa ăn. Đây có thể là yếu tố giúp giải thích tỷ lệ sâu răng của chúng tôi thấp hơn các nghiên cứu sâu răng trên người trưởng thành bình thường.

Tỷ lệ sâu răng của chúng tôi có nét tương đồng với kết quả nghiên cứu của tác giả Nandini NS $^{3}$ năm 2003 khi nghiên cứu trên 150 trẻ khiếm thị với tỷ lệ sâu răng là $37.3 \%$.

Chỉ số DMFT là 3,06; chỉ số DMFT của nam là 
2.98, DMFT của nữ là 3.13. Trung bình mỗi người khiếm thị có 0.88 răng sâu, 0.22 răng được trám. DMFT trên nhóm đối tượng nghiên cứu thấp hơn DMFT trong nghiên cứu của tác giả B. Daniel ${ }^{4}$ và cộng sự (2017) trên 404 người khiếm thị trong độ tuổi từ 15 đến 30 tuổi với DMFT là 4,5. Khi so sánh với báo cáo điểu tra sức khỏe răng miệng toàn quốc năm 2001 của tác giả Trần Văn Trường ${ }^{2}$ với DMFT là 1.87 và tác giả Ajami ${ }^{5}$ và cộng sự nghiên cứu năm 2007 trên 1621 trẻ bao gồm khiếm thị, tâm thần và khiếm thính với DMFT là 2,68 thì DMFT trong nghiên cứu của chúng tôi cao hơn. Lý giải cho sự khác biệt này có thể do nghiên cứu của chúng tôi tiến hành trên số lượng ít, lứa tuổi từ 18 đến trên 60 tuổi còn nghiên cứu của các tác giả trên tập trung trong một độ tuổi nhất định và số lượng cỡ mẫu nghiên cứu lớn hơn.

\section{KẾT LUÂNN}

Tỷ lệ sâu răng ở mức thấp $41.7 \%$. Chỉ số DMFT là 3.06, DT là 0.88 ; MT 1.96; là FT là 0.22. Qua kết quả nghiên cứu, chúng tôi đễ xuất cần thực hiện nhiều nghiên cứu với cõ mẫu lớn hơn trên người khiếm thị để có những biện pháp hỗ trợ giáo dục, can thiệp điêu trị kịp thời, giúp cho người khiếm thị được quan tâm, chăm sóc tốt hơn.

\section{TÀI LIỆU THAM KHẢO}

1. Pham Thi Diêp. Khảo sát tình trang bênh sâu răng, viêm lợi và nhu câu điều trị của học sinh khiểm thi trường Nguyễn Đình Chiểu Hà Nô̂i năm 2013. Khóa luận tốt nghiệp bác sỹ Y khoa. 2014.

2. Trân Văn Trường, Lâm Ngọc Ân, Trịnh Đình Hải. Điều tra sức khỏe răng miênng toàn quốc. Nhà xuất bản Y học. Published online 2002:12-18.

3. Nandini NS. New insights into improving the oral health of visually impaired children. J Indian Soc Pedod Prev Dent. Published online 2003:21(4), 142-143.

4. John JR, Daniel B, Paneerselvam D, Rajendran G. Prevalence of Dental Caries, Oral Hygiene Knowledge, Status, and Practices among Visually Impaired Individuals in Chennai, Tamil Nadu. Int J Dent. 2017;2017. doi:10.1155/2017/9419648

5. Ajami BA, Rezay YA, Shabzen. Dental treatment Needs of Children with Disabilities. J Dent Res, Den Clin, Dent Prospects. Published online 2007:1,2.

\section{NHẬN XÉT HIỆU QUẢ CỦA ATOSIBAN TRONG ĐIỀU TRI DỌA ĐẺ NON TẠI BỆNH VIỆN PHỤ SẢN TRUNG ƯO'NG}

\section{TÓM TẮT}

Mục tiêu: Nhận xét hiệu quả giảm co của Atosiban trong điều trị dọa đẻ non tại Bệnh viện Phụ sản Trung Ương. Đối tượng và phương pháp nghiên cứu: Nghiên cứu mô tả, hồi cứu nhằm xác định hiệu quả giảm co của Atosiban trong điều trị dọa đẻ non ở thai phụ. Kết quả: Tỷ lệ điều trị thành công cắt cơn co tử cung $>48$ giờ của Atosiban là $87,5 \%$, hiêu quả giảm được cơn co của Atosiban tại từng thời điểm $>3$ giờ có tỷ lệ cao nhất $42,73 \%$.Sử dụng Atosiban khi cơn co tử cung $<2$, cường độ $<60 \%$ cho tỷ lệ thành công tốt nhất. Kết luận: Atosiban có hiệu quả điều trị dọa sinh non thời gian duy trì thai kỳ được 48 giờ khá cao đây là thời gian cần thiết cho tác dụng tối đa của thuốc trưởng thành phổi

Tư khóa: Đẻ non, Atosiban

\section{SUMMARY}

\section{COMMENTS ON THE EFFICACY OF ATOSIBAN IN THE TREATMENT OF THREATENING PRETERM}

*Trường Đại học Y Hà Nội

Chịu trách nnhiệm chính: Nguyễn Mạnh Thắng

Email: bsnguyenmanhthang@gmail.com

Ngày nhận bài: 2/4/2021

Ngày phản biên khoa hoc: 16/4/2021

Ngày duyệt bài: $15 / 5 / 2021$
Nguyễn Mạnh Thắng*

\section{LABOR IN NATIONAL HOSPITAL OF OBSTETRICS AND GYNECOLOGY}

Objective: Comments on the efficacy of atosiban in the treatment of threatening preterm labor in national hospital of Obstetrics and Gynecology. Methods: A descriptive study, retrospective to determine the effect of Atosiban contraction in the treatment of threatening preterm labor in pregnant women. Result: The rate of Atosiban's successful treatment of uterine contraction> 48 hours is $87.5 \%$, the effect of Atosiban contraction reduction at> 3 hours has the highest rate of $42.73 \%$. Using Atosiban when uterine contractions $<2$, intensity $<60 \%$ for the best success rate. Conclustion: Atosiban is effective in treating preterm birth, maintaining a pregnancy of 48 hours is quite high, which is the time needed for maximum effectiveness of the lung maturation drug.

Keyword: Preterm birth, Atosiban

\section{I. ĐĂT VẤN ĐỀ}

Đẻ non được định nghĩa là sinh trước khi hoàn thành 37 tuần tuổi thai. Đẻ non xảy ra ở khoảng 5-15\% tổng số những trường hợp sinh. Trẻ đẻ non có nguy cơ mắc bệnh cao và tỷ lệ tử vong chu sinh càng cao khi tuổi thai càng nhỏ, với tỷ lệ vào khoảng 6 - 7\% số trường hợp sinh ở các nước đã phát triển. Tại Hoa Kỳ, tỷ lệ này là 